\title{
Timing of percutaneous endoscopic gastrostomy in COVID-19 infection: Endoscopic surgery unit experience
}

\author{
COVID-19 enfeksiyonunda perkütan endoskopik gastrostomi zamanlaması: Endoskopik cerrahi ünite \\ deneyimi \\ Necattin Frrat ${ }^{1}$, Mehmet Aziret ${ }^{2}$, Barış Mantoğlu ${ }^{1}$, Recayi Çapoğlu ${ }^{3}$, Hakan Demir ${ }^{3}$, Enis Dikicier ${ }^{1}$, Emrah Akın \\ 1, Tarık Harmatepe ${ }^{3}$, Fatih Altıntoprak ${ }^{1}$
}

\section{Abstract}

Aim: The COVID-19 pandemic has negatively affected the whole world and health systems. Although the literature includes recommendations regarding the timing of Percutaneous endoscopic gastrostomy (PEG) in COVID-19 patients, there are no significant clinical studies yet. Therefore, we aim to contribute to the literature by sharing our data on this subject.

Materials and Methods: Patients who underwent PEG between March 2020 and March 2021 were retrospectively evaluated in our clinic. The patients were compared statically in terms of age, gender, medical indications, comorbid diseases, hospitalization in the intensive care unit (ICU), blood tests, and post-intervention complications. PEG was inserted routinely in PCR-negative patients. Patients who underwent PEG were compared as outpatients and inpatients in the ICU. Moreover, patients who underwent PEG while hospitalized in the ICU were divided into two groups according to the presence of COVID-19 infection; patients noninfected with COVID-19 (group 1) and COVID-19 infected patients (group 2).

Results: PEG was performed in 66 patients during the COVID-19 pandemic. These patients predominantly consisted of those with SVH, Alzheimer's, or traumatic brain injury. In the present study, thirty-two (\%48.5) patients were female with a mean age of $69.4 \pm 17.6$, and forty-seven patients underwent PEG in the ICU Furthermore, eleven of these patients were COVID-19, infected patient group (group-2). There was no statistica difference in blood albumin levels, CRP, hemogram results, and 30-day mortality results between group 1 and group $2(\mathrm{P}>0.05)$.

Conclusion: PEG is a minimally invasive intervention that is commonly used for enteral feeding. The timing of the procedure is crucial for inpatients with COVID-19. Although the most appropriate timing is the 30th day after the COVID-19 infection process, we think that PEG may insert on the 10th day in eligible patients.

Keywords: Percutaneous Endoscopic Gastrostomy, COVID-19, infection, Cerebrovascular disease, minimally invasive
1 Sakarya University Faculty of Medicine, Department of General Surgery, Sakarya, Turkey.

2 Sakarya University Training and Research Hospital, Department of Gastroenterological Surgery, Sakarya, Turkey.

3 Sakarya University Training and Research Hospital, Department of General Surgery, Sakarya, Turkey.

\section{NF: 0000-0003-0684-8187}

MA: 0000-0001-6758-7289

BM: 0000-0002-2161-3629

RC: 0000-0003-4438-4301

HD: 0000-0001-5973-4605

ED: 0000-0002-5074-0299

EA: 0000-0003-0224-3834

TH: 0000-0003-2888-7646

FA: 0000-0002-3939-8293

Ethics Committee Approval: This study was approved by the Sakarya University Medical Faculty Ethics Committee (ID: 71522473050.01.04-21455-212, date: 05.03.2021).

Etik Kurul Onayı: Bu çalışma Sakarya Üniversitesi Tıp Fakültesi Etik Kurulu tarafindan onaylanmıştır (ID: 71522473-050.01.04-21455-212, date: 05.03.2021).

Conflict of Interest: No conflict of interest was declared by the authors.

Çıkar Çatışması: Yazar çıkar çatışması bildirmemiştir.

Financial Disclosure: The authors declared that this case has received no financial support.

Finansal Destek: Yazarlar bu çalışma için finansal destek almadıklarını beyan etmişlerdir.

Geliş Tarihi / Received: 05.10.2021

Kabul Tarihi / Accepted: 02.12.2021

Yayın Tarihi / Published: 09.12.2021

Sorumlu yazar / Corresponding author:

Necattin Firat

Adres/Address: Department of General Surgery, Sakarya University Faculty of Medicine, Adnan Menderes Cd. Saglik Sok. No:195 54100 Adapazari/Sakarya, Turkey. e-mail: necattinf@gmail.com Tel/Phone: +905053725041

\section{Copyright (C) ACEM}




\section{Introduction}

Coronavirus, which has spread rapidly worldwide, is a respiratory RNA virus that can lead to clinical issues with severe respiratory failure [1]. Symptomatic patients often transmit the infection through sizeable droplets produced during coughing and sneezing [2]. As a result of this global enigma, new guidelines to protect patients and healthcare professionals from confirmed and suspected cases are frequently issued. At the same time, health authorities strive to establish the optimal approach [3]. Recommendations for invasive surgical procedures in patients infected with COVID-19 have also been reviewed, and a delay to surgery of 3-4 weeks is recommended in the case of patients who cannot be fed orally and so require feeding tube insertion [4].

In 1980, Gauderer et al. described the percutaneous endoscopic gastrostomy (PEG) primarily for elderly patients with swallowing difficulties linked to neurological disorders $[5,6]$. This minimally invasive method is more advantageous than other procedures, providing a secure long-term feeding route with low morbidity and complication rates $[7,8]$. Therefore, its efficiency and practicality make PEG a preferred intervention for long-term enteral nutrition [9].

Currently, the literature includes minimal data on the topic of placing PEG in COVID-19 patients. Therefore, this study aims to evaluate PEG applications in our center over one year during the pandemic and present our data on PEG timing in patients infected with COVID-19.

\section{Material and methods}

\section{Patients and Ethics}

This study includes patients who underwent PEG in the General Surgery Endoscopy unit between March 2020 and March 2021, incorporating the first and second pandemic waves. The PEG procedure was performed on patients with gastrointestinal system continuity but could not take oral nutrition for about 30 days. Data concerning patient age, gender, medical indications, comorbid diseases, hospitalization in intensive care unit (ICU) at the time of the procedure, laboratory parameters, PCR tests, and complications were accessed from patient records and documented. First, the patients were compared as inpatients and outpatients in the ICU. Second, the patients were divided into two groups: patients in the intensive care unit not infected with COVID-19 (group 1) and patients infected with COVID-19 (Group 2). The groups were compared in terms of clinical features. Approval for this study was granted by the ethics committee of Sakarya University (05/03/2021; 71522473-050.01.04-21455-212).

Patient selection process, diagnosis of COVID-19, and prevention of infection

PEG was administered to patients who were PCR negative. The procedure was not performed on patients with impaired bleeding profiles or symptoms of sepsis. COVID-19 diagnosis was made in symptomatic patients through PCR positivity and thorax computed tomography (CT) findings. All patients were given a COVID-19 PCR test before the procedure. In both PCR-positive patients and cases diagnosed with COVID19 by tomography, PEG was delayed until after a negative PCR could be obtained, and symptoms of the disease had passed. While standard precautions were taken for non-virus-infected patients (wearing of masks by all team members and 30-minute room ventilation), special precautions were taken for infected patients (N95 mask, visor, disposable gowns, 1-hour room ventilation, and disinfection of the room after the procedure).

\section{PEG procedure}

Before the procedure, patients were monitored, and nasal oxygen was initiated at 4-6 L/minute. The patients received 1-2 mg midazolam, and one $\mathrm{mcg} / \mathrm{kg}$ fentanyl, with $0.5 \mathrm{mg} / \mathrm{kg}$ propofol added after the procedure had started for sedation. The cases got a lidocaine hydrochloride spray and $2 \mathrm{cc}$ prilocaine to the skin at the incision site for local oropharyngeal anesthesia. Antibiotic prophylaxis with cefazolin sodium was administered to the patients, except for cases already under antibiotic treatment. The patients did not receive enteral feeding for at least 8 hours before the procedure. An experienced team performed the process in the general surgery endoscopy unit.

The PEG procedure was performed by applying the "pull-through" technique by observing the indentation made by the finger and the transillumination created by the endoscope through the stomach. As a standard, a 20Fr PEG tube was placed in all patients. All interventions were made using a Fujinon VP4450HD (Fujifilm company, Minato-ku, Tokyo, Japan) fiber endoscope. Enteral feeding was started 16 hours after the feeding tube was inserted.

In the present study, one patient whose PCR test was positive during the peg procedure and three patients who could not have the PEG procedure were excluded. In addition, while endoscopic gastric tube revisions were included in the study, gastric tube replacements performed without endoscopy were excluded.

\section{Statistical analysis}

The frequency of sociodemographic, clinical data, and descriptive statistics were calculated as numbers, distribution, and percentages. The control groups, continuous variables with normal distribution were compared using the independent sample t-test; variables not showing a normal distribution with the Mann-Whitney $U$ test, and independent group rates were compared using Fisher's exact test. A p-value $<0.05$ was considered significant. Analyses were performed using SPSS statistical software (IBM SPSS Statistics, Version 26.0. Armonk, NY: IBM Corp.).

\section{Results}

During the pandemic, 66 patients had appropriate indications for PEG, and these procedures were planned. However, PEG was not performed because of co-morbidities, high-risk American Society of Anesthesiologists (ASA) scores, unsuitable anatomy or infection status. Patients undergoing PEG frequently had cerebrovascular disorder (CVD), Alzheimer's disease, or traumatic brain injury. The primary and comorbid conditions of these patients were shown in Table 1.

Most patients were in the ICU at the time of the procedure. A comparison was made between the intensive care patients and those who were prepared for PEG in the outpatients' clinic. (Table 2). The results of this comparison showed the 30 day mortality rate to be significantly higher in intensive care patients $(\mathrm{p}=0.01)$. In addition, the $\mathrm{C}$ reactive protein $(\mathrm{CRP})$ and white blood count (WBC) values of the patients hospitalized in the intensive care unit were significantly higher $(\mathrm{p}=0.001$ and $\mathrm{p}$ $=0.01$, respectively), while albumin and hematocrit levels were significantly lower $(\mathrm{p}<0.05)$. All of the virus-infected patients were inpatients in the intensive care unit (Table 2).

In the present study, ten patients had complications with their feeding tubes due to the deterioration of the tube in five patients and wound infection in the remaining five patients. In comparison, the antibiotic treatment was sufficient in the five patients who had wound infection; in the remaining cases, the tube had to be removed and replaced with a new feeding tube. 
The diagnosis of virus-infected patients (group 2), who were all in intensive care, was made by PCR in 4 patients and tomography in 7 patients. Patients with ICU have been divided into two groups: non-virus-infected (group 1) and virus-infected (group1) (Table 3). There was no significant difference between the two groups regarding age, gender, blood albumin levels, WBC and hematocrit values, blood gas, or lactate values (Table 3).

Table1. Primary diseases and comorbid diseases of patients with PEG

\begin{tabular}{lcc} 
& All Patients (n\%) & $\begin{array}{c}\text { Patients with } \\
\text { COVID-19 }(\mathrm{n} \%)\end{array}$ \\
\hline Diagnosis & & \\
Cerebrovascular disease & $25(37.9)$ & $5(45.4)$ \\
Alzheimer disease & $13(19.7)$ & $3(27.3)$ \\
Trauma & $7(10.6)$ & \\
General condition disorder & $4(6.1)$ & $1.1(9.1)$ \\
Hypoxic or anoxic brain injury & $5(7.6)$ & $1.1(9.1)$ \\
Cranial tumor & $3(4.6)$ & $1.1(9.1)$ \\
Dementia & $2(3.0)$ & \\
Parkinson disease & $23.0)$ & \\
Amyotrophic lateral sclerosis & $1(1.5)$ & \\
Cerebral palsy & $1(1.5)$ & \\
Polyneuropathy & $1(1.5)$ & \\
Lip or tongue cancer & $1(1.5)$ & \\
Esophageal cancer & $1(1.5)$ & \\
\hline Total & $66(100)$ & $11(100)$ \\
\hline Co-Morbidities & & \\
Hypertension & $20(29.9)$ & $4(33.3)$ \\
Senility & $17(25.4)$ & $6(50)$ \\
Lung failure & $9(13.4)$ & $5(41.7)$ \\
Coronary artery disease & $8(11.9)$ & $1(8.3)$ \\
Diabetes Mellitus & $8(11.9)$ & $2(16.7)$ \\
Chronic obstructive lung disease & $7(10.4)$ & $1(8.3)$ \\
Malignity & $6(9.0)$ & \\
Congestive heart failure & $5(7.5)$ & $2(16.7)$ \\
Thrombocytopenia & $2(3.0)$ & \\
Schizophrenia & $1(1.5)$ & \\
Substance abuse & $1(1.5)$ & \\
None & $23(34.3)$ & \\
\hline Total & 106 & 21 \\
\hline & & \\
\hline & &
\end{tabular}

\section{Discussion}

The COVID-19 infection is associated with a high mortality rate in patients with multiple co-morbidities. Patients undergoing PEG procedures have had generally long-term and severe co-morbidities. Therefore, the timing of PEG insertion is essential in the presence of the co-existence of the COVID and PEG process.

The ICU-specific nutrition guidelines have suggested early nutrition (EN) within 24-48 hours following the intervention [10]. Furthermore, the influence of hypoalbuminemia, serum C-reactive protein levels, metastatic cancer, and other comorbid diseases on mortality after PEG is well-documented [11]. Both albumin levels and hemogram values of the patients undergoing PEG in the ICU were significantly lower than in the other patients; their CRP levels were significantly higher; and the 30-day mortality was also higher in these ICU patients, as expected. Thus, the importance of early enteral nutrition in this patient group is evident.

Wound infection is the most common complication associated with the PEG procedure. The surgical site infection can frequently respond to antibiotic treatment. [12]. In half of our patients, the feeding tube had to be removed due to wound infection, but after medical treatment, the PEG was reinserted in a second session.

A positive PCR test is used to make a COVID-19 diagnosis in clinically suspected patients. In case of a false negative, thorax CT may assist the diagnosis [13]. In this study, tomography was used to confirm the diagnosis of COVID-19 in 7 patients.
Table 2. Descriptive statistics of Outpatient and ICU patients

\begin{tabular}{lccc} 
& $\begin{array}{c}\text { Insertion of PEG } \\
\text { in outpatient } \\
(\mathrm{n}=19)\end{array}$ & $\begin{array}{c}\text { Insertion of PEG } \\
\text { in ICU } \\
(\mathrm{n}=47)\end{array}$ & $P$ \\
\hline Gender (M/F) & $12(63.2 \%) / 7(36.8)$ & $21(44.7) / 26(55.3)$ & 0.155 \\
Age (year) & $68.5 \pm 22.8$ & $69.7 \pm 15.4$ & 0.616 \\
CRP (mg/L) & $45.8 \pm 45.7$ & $98.7 \pm 61.0$ & $<0.01$ \\
Albumin (g/L) & $32.5 \pm 6.9$ & $26.4 \pm 4.7$ & $<0.01$ \\
WBC (K/uL) & $7.2 \pm 2.6$ & $9.2 \pm 2.9$ & 0.01 \\
Hematocrit (\%) & $35.1 \pm 4.2$ & $29.4 \pm 5.4$ & $<0.01$ \\
Hemoglobin (g/dl) & $11.4 \pm 1.4$ & $9.6 \pm 1.7$ & $<0.01$ \\
Complication and mortality & \multicolumn{4}{|c}{} \\
Diagnosis of COVID-19 & 0 & $11(23.4 \%)$ & $0.014^{*}$ \\
Leakage around the PEG & $2(10.5 \%)$ & $7(14.9 \%)$ & $0,901^{*}$ \\
Alteration of the PEG & $6(31.6 \%)$ & $4(8.5 \%)$ & 0.017 \\
First 30-day mortality (\%) & 0 & $12(25.5 \%)$ & 0.01 \\
\hline CRP: C-Reactive protein: Intensive care unit, PEG: Percutaneous endoscopic gastrostomy, \\
WBC: White blood cell, Mann Whitney U test, *,Fisher Exact
\end{tabular}

Table 3. Descriptive statistics of Group 1 and Group 2

\begin{tabular}{lccc} 
& $\begin{array}{c}\text { Patients without } \\
\text { COVID-19 } \\
\text { (Group 1) } \\
(\mathrm{n}=36)\end{array}$ & $\begin{array}{c}\text { Patients with } \\
\text { COVID-19 } \\
\text { (Group 2) } \\
(\mathrm{n}=11)\end{array}$ & $\mathrm{P}$ \\
\hline Patients (female/male) & $\begin{array}{c}\text { P/22 }(38.9 / 61.1) \\
\text { Age (year) }\end{array}$ & $6 / 5(54.5 / 45.5)$ & 0.369 \\
CRP (mg/L) & $98.3 \pm 14.9$ & $72.6 \pm 16.9$ & 0.421 \\
Albumin (g/L) & $26.5 \pm 4.6$ & $102.8 \pm 58.8$ & 0.885 \\
WBC (K/uL) & $9.2 \pm 3.1$ & $25.0 \pm 4.1$ & 0.511 \\
Hematocrit (\%) & $29.6 \pm 5.3$ & $9.5 \pm 2.5$ & 0.757 \\
Hemoglobin (g/dl) & $9.7 \pm 1.7$ & $27.8 \pm 4.9$ & 0.199 \\
Arterial blood gases ph & $7.4 \pm 0.1$ & $9.0 \pm 1.5$ & 0.150 \\
Complication and the & & $7.4 \pm 0.06$ & 0.680 \\
hospital mortality & $7(21.2 \%)$ & & \\
Leakage around the PEG & - & 0 & \\
The insertion time of PEG & & $30(10 / 50) *$ & \\
after COVID-19 diagnosis & $9(25.0 \%)$ & & 0.295 \\
(days) & & $3(27.3 \%)$ & \\
Hospital mortality (First- & & & \\
30 days) (\%) & & & \\
\hline CRP: C-Reactive protein, PEG: Percutaneous endoscopic gastrostomy, WBC: White blood
\end{tabular}

CRP: C-Reactive protein, PEG: Percutaneous endoscopic gastrostomy, WBC: White blood cell, Mann Whitney U test, * median(min/max)

In our study, there was a strong association between virus-infected patients who underwent PEG and COVID-19. The literature suggests that COVID-19 may be more severe in individuals with a history of COVID-19 and describes the effects of accompanying cardiovascular diseases in these patients [14]. Morbidity and mortality rates are higher in COVID-19 infected patients with comorbidities such as diabetes, cardiovascular disease, chronic respiratory diseases, and in patients over the age of 60 [15]. Patients who undergo PEG have multiple risk factors. After the early insertion of PEG, an increase in 30-day mortality can be expected. In the cases in this study, the 30-day mortality rate was similar to other patients hospitalized in the ICU.

Patients can be infected by the environment retching, coughing, and drooling during upper GI endoscopy. Therefore, measures should be taken to protect both patients and healthcare professionals in the pandemic period [16, 17]. It should be emphasized that at the peak of the pandemic, only urgent endoscopic procedures should be performed and that the decision to place endoscopic feeding tubes should be made on a patientby-patient basis [18]. Moreover, PEG intervention should not be achieved unless complications related to the nasoenteral tube develop in active infection [19]. As perioperative COVID-19 conditions are known to carry an increased risk of death and pulmonary complications, international collaborative studies recommend delaying non-urgent procedures, where possible [20]. Meanwhile, current studies also suggest the optimal time for surgical intervention to be after an asymptomatic period of 7 weeks following virus infection [21]. Also, for PEG, a delay of 3-4 weeks with the pull technique is recommended [4].

This study has some limitations. First, there was a small sample size and retrospective planned research. On the other 
hand, the present study can be critical for emphasizing the timing of the PEG procedure in patients with PEG.

PEG, which is a minimally invasive procedure, is widely utilized to supply enteral nutrition. Since surgical procedures increase the severity of the disease in COVID-19 patients, the timing of the intervention is essential in infected patients. Although the most appropriate timing is on the 30th day after the infection has cleared, it is possible to use PEG on the 10th day in proper patients who have a negative PCR and no disease symptoms..

\section{References}

1. Del Rio C, Malani PN. 2019 Novel Coronavirus-Important Information for Clinicians. JAMA. 2020;323:1039-40.

2. Rothe C, Schunk M, Sothmann P, Bretzel G, Froeschl G, Wallrauch C, et al. Transmission of 2019-nCoV Infection from an Asymptomatic Contact in Germany. $\mathrm{N}$ Engl $\mathrm{J}$ Med. 2020;382:970-1.

3. Karaca AS, Ozmen MM, Uçar AD, Yasti AÇ, Demirer S. COVID-19'lu Hastalarda Genel Cerrahi Ameliyathane Uygulamaları. Turk J Surg. 2020;36:VI-X.

4. Goyal H, Perisetti A, Tharian B. Percutaneous Endoscopic Gastrostomy tube placement in COVID-19 patients: Multidisciplinary approach. Dig Endosc. 2021;33:209.

5. Gauderer MW, Ponsky JL, Izant RJ. Gastrostomy without laparotomy: a percutaneous endoscopic technique. J Pediatr Surg. 1980;15:872-5.

6. Özer Etik D, Suna N, Öcal S, Selçuk H. Percutaneous endoscopic gastrostomy in older patient population. Endoscopy Gastrointestinal 2018;26:6-11.

7. Hucl T, Spicak J. Complications of percutaneous endoscopic gastrostomy. Best Pract Res Clin Gastroenterol. 2016;30:769-81.

8. Aziret M, Karaman K, Ercan M, Celebi F, Akdeniz Y, Ebiloglu T, et al. Assessment of risk factors on morbidity and mortality in patients undergoing percutaneous endoscopic gastrostomy. Ann Med Res. 2018;25:400.

9. Haqqi SAUH, Farrukh SZUI, Dhedhi AS, Siddiqui AR, Muhammad AJ, Niaz SK. Percutaneous endoscopic gastrostomy; success and outcome of a novel modality for enteral nutrition. JPMA J Pak Med Assoc. 2020;70 1795-8.

10. McClave SA, Taylor BE, Martindale RG, Warren MM, Johnson DR, Braunschweig C, et al. Guidelines for the Provision and Assessment of Nutrition Support Therapy in the Adult Critically Ill Patient: Society of Critical Care Medicine (SCCM) and American Society for Parenteral and Enteral Nutrition (A.S.P.E.N.). JPEN J Parenter Enteral Nutr. 2016;40:159-211.

11. Stein DJ, Moore MB, Hoffman G, Feuerstein JD. Improving AllCause Inpatient Mortality After Percutaneous Endoscopic Gastrostomy. Dig Dis Sci. 2021;66:1593-1599.

12. Blumenstein I, Shastri YM, Stein J. Gastroenteric tube feeding: Techniques, problems and solutions. World J Gastroenterol WJG. 2014;20:8505-24.

13. Ai T, Yang Z, Hou H, Zhan C, Chen C, Lv W, et al. Correlation of Chest CT and RT-PCR Testing for Coronavirus Disease 2019 (COVID-19) in China: A Report of 1014 Cases. Radiology. 2020;296:E32-E40.

14. Siepmann T, Sedghi A, Barlinn J, de With K, Mirow L, Wolz M, et al. Association of history of cerebrovascular disease with severity of COVID-19. J Neurol. 2021;268:773-84.

15. Ejaz H, Alsrhani A, Zafar A, Javed H, Junaid K, Abdalla AE, et al. COVID-19 and comorbidities: Deleterious impact on infected patients. J Infect Public Health. 2020;13:1833-9.

16. Iacucci M, Cannatelli R, Labarile N, Mao R, Panaccione R, Danese $\mathrm{S}$, et al. Endoscopy in inflammatory bowel diseases during the COVID-19 pandemic and post-pandemic period. Lancet Gastroenterol Hepatol. 2020;5:598-606.

17. Tian T, Bugaev N, Johnson BP, Mahoney E, Nilson J, Sekhar P, et al. Novel Tracheostomy and Percutaneous Endoscopic Gastrostomy Technique for COVID-19 Patients in a Nonnegative Pressure Environment. Am Surg. 2020;3134820960072.

18. Sinonquel P, Roelandt P, Demedts I, Gerven LV, Vandenbriele C, Wilmer A, et al. COVID-19 and gastrointestinal endoscopy: What should be taken into account? Dig Endosc. 2020;32:723-31.

19. Micic D, Wall E, Semrad C. Nutrition Support in the ICU-A Refresher in the Era of COVID-19. Am J Gastroenterol. 2020;115:1367-70.
20. COVIDSurg Collaborative. Mortality and pulmonary complications in patients undergoing surgery with perioperative SARS-CoV-2 infection: an international cohort study. Lancet Lond Engl. 2020;396:27-38.

21. COVIDSurg Collaborative; GlobalSurg Collaborative. Timing of surgery following SARS-CoV-2 infection: an international prospective cohort study. Anaesthesia. 2021;76:748-58. 